Review

\title{
Beneficial Effects of Walnuts on Cognition and Brain Health
}

\author{
Abha Chauhan * and Ved Chauhan \\ New York State Institute for Basic Research in Developmental Disabilities, Staten Island, New York, NY 10314, \\ USA; ved.chauhan@opwdd.ny.gov \\ * Correspondence: abha.chauhan@opwdd.ny.gov; Tel.: +1-718-494-5258; Fax: +1-718-698-7916
}

Received: 31 January 2020; Accepted: 18 February 2020; Published: 20 February 2020

Abstract: Oxidative stress and neuroinflammation have important roles in the aging process, mild cognitive impairment (MCI), Alzheimer's disease (AD), and other brain disorders. Amyloid beta protein $(A \beta)$ is the main component of amyloid plaques in the brains of people with AD. Several studies suggest that $A \beta$ increases the generation of free radicals in neurons, which leads to oxidative damage and cell death. A $\beta$ can also induce neuroinflammation by increasing pro-inflammatory cytokines and enzymes. Walnuts contain several components that have antioxidant and anti-inflammatory effects. Animal and human studies from our and other groups suggest that supplementation with walnuts in the diet may improve cognition and reduce the risk and/or progression of MCI and AD. In the transgenic $\mathrm{AD}$ mouse model (AD-tg), we have reported the beneficial effects of a diet with walnuts on memory, learning, motor coordination, anxiety, and locomotor activity. Human clinical trials have also suggested an association of walnut consumption with better cognitive performance and improvement in memory when compared to baseline in adults. Our recent study in AD-tg mice has shown that a walnut-enriched diet significantly improves antioxidant defense and decreases free radicals' levels, lipid peroxidation, and protein oxidation when compared to a control diet without walnuts. These findings suggest that a diet with walnuts can reduce oxidative stress by decreasing the generation of free radicals and by boosting antioxidant defense, thus resulting in decreased oxidative damage to lipids and proteins. An in vitro study with synthetic $A \beta$ showed that walnut extract can inhibit $A \beta$ fibrillization and solubilize the preformed $A \beta$ fibrils, suggesting an anti-amyloidogenic property of walnuts. Because it takes many years for cognitive impairment and dementia to develop, we suggest that early and long-term dietary supplementation with walnuts may help to maintain cognitive functions and may reduce the risk of developing, or delay the onset and/or slow the progression of, $\mathrm{MCI}$ and dementia by decreasing $\mathrm{A} \beta$ fibrillization, reducing oxidative damage, increasing antioxidant defense, and decreasing neuroinflammation. Furthermore, several animal and human studies have suggested that walnuts may also decrease the risk or progression of other brain disorders such as Parkinson's disease, stroke, and depression, as well as of cardiovascular disease and type 2 diabetes. Together, these reports suggest the benefits of a walnut-enriched diet in brain disorders and in other chronic diseases, due to the additive or synergistic effects of walnut components for protection against oxidative stress and inflammation in these diseases.

Keywords: Alzheimer's disease; amyloid beta protein; dementia; depression; oxidative stress; inflammation; mild cognitive impairment; nutrition; walnuts

\section{Introduction}

Dementia is defined by age-related progressive impairment of cognitive function in several domains (memory, learning, judgment, orientation, language, and comprehension), thereby affecting the daily activities of life and social function in elderly people. The prevalence of dementia has been 
increasing over the years because of an increase in the aging population. In 2015,47 million people were suffering from dementia worldwide, and 131 million people are estimated to have dementia by 2050 [1]. Dementia occurs mainly in people older than 65 years of age, when comorbidity is also a common occurrence. It is generally preceded by mild cognitive impairment (MCI). The current estimate is that $33 \%$ of elderly people die with dementia. The annual cost of dementia care globally is roughly $\$ 818$ billion.

Alzheimer's disease (AD) is a devastating neurodegenerative disorder that gradually leads to memory loss and decline of cognitive functions over a time period of 5-20 years. Although there are many types of dementia, AD ranks as the most common cause of dementia among elderly people, and it accounts for over $60 \%$ of dementia cases. Vascular dementia is the second most common dementia, followed by dementia with Lewy bodies. AD affects about 25 million people worldwide, including 5.5 million people in the United States. A total of $10 \%$ of the population over 65 years of age, and nearly $50 \%$ of people over 85 years of age, suffer from AD. The neuropathological hallmarks of AD include neuronal loss and progressive accumulation of fibrillar amyloid beta protein $(\mathrm{A} \beta)$ as amyloid plaques, and of paired helical filaments as neurofibrillary tangles in the brain [2]. In AD, the major amyloid protein is amyloid beta protein $(\mathrm{A} \beta)$ of 40 or 42 amino acids, which exists as soluble or fibrillar $\mathrm{A} \beta$. Neuropathological changes in AD occur slowly over decades before the clinical symptoms of dementia are diagnosed.

MCI is considered an intermediate state between healthy aging and early dementia [1]. The prevalence of MCI is $10 \%-20 \%$ of people 65 years of age or older. Although these people can perform daily activities, they are considered at higher risk of developing dementia within 3-10 years. Therefore, this time period provides a potential targeted intervention window to reduce the risk, prevent, or delay the onset and progression of cognitive impairment and dementia. MCI is classified as either amnestic MCI (with impaired memory) or non-amnestic MCI (no effect on memory). About $50 \%$ of people with amnestic MCI develop dementia in three years.

About $35 \%$ of dementia cases are attributed to modifiable risk factors, which include vascular (cardiovascular disease, hypertension, stroke), metabolic (diabetes, midlife obesity), head trauma, depression, and lifestyle factors (diet quality, alcohol abuse, sleep deprivation). It is estimated that $33 \%$ of dementia cases can be delayed or prevented through better management and targeted intervention of these risk factors, particularly hypertension, depression, diabetes, and obesity [1]. The association between diet and health is becoming increasingly clear, with extensive evidence that plant foods rich in flavonoids and phenols are efficient as defensive antioxidants, thus reducing oxidative stress, which is known to contribute to the pathophysiology of many diseases, including neurological disorders, cardiovascular disease (CVD), hypertension, and diabetes. In the following sections, we review evidence that early intervention with a walnut-enriched diet can reduce the risk and/or delay the onset or slow the progression of cognitive decline and dementia because of (a) the elevated oxidative stress and inflammation involved in the aging process and dementia and (b) the antioxidant and anti-inflammatory components of walnuts.

\section{Oxidative Stress in Aging, MCI, and AD}

Oxidative stress is caused by an imbalance of free radicals' levels and antioxidant defense in the body [3]. Increased levels of free radicals are toxic, and if not removed, they react with lipids, protein, and nucleic acids in the cell and damage cellular functions. As a result, oxidative stress affects membrane properties such as fluidity, enzymes' activities, ion transport, and cross-linking of proteins. Enhanced oxidative damage eventually leads to cell death. The brain is particularly vulnerable to oxidative stress because it consumes $20 \%$ of the total body intake of oxygen (due to its higher energy requirement), and it has limited antioxidant capacity and higher amounts of unsaturated lipids.

Several studies with human and experimental models suggest increased oxidative stress [4-7] and inflammation [7-10] to be important features in the aging process and in AD, which can cause neuronal dysfunction and death. Enhanced oxidative damage as evidenced by increased lipid peroxidation, 
protein oxidation, and DNA oxidation has been demonstrated in the brain, cerebrospinal fluid (CSF), and blood samples of individuals with AD. Increased oxidative damage is also reported in the brains and blood samples of individuals with MCI, and in the CSF of individuals with early signs of dementia [11-13]. Several reports suggest that $A \beta$ induces neuronal death by increasing oxidative stress [14]. A $\beta$ generation is also increased because of oxidative stress, which then causes more oxidative damage.

\section{Inflammation in Aging, MCI, and AD}

Several studies suggest that neuroinflammation cascades mediated by activated microglia cells, which release proinflammatory cytokines, have a detrimental role in AD [7-10]. Higher numbers of activated microglia and astrocytes, and elevated levels of inflammatory cytokines, namely, interleukin (IL)-6, IL-1 $\beta$, and tumor necrosis factor- $\alpha$ (TNF- $\alpha$ ), have been reported in aging brains and AD brains. $\mathrm{A} \beta$ has also been reported to activate microglia cells, which leads to enhanced production of proinflammatory cytokines (IL-1 $\beta$, IL-6, and TNF- $\alpha$ ) and stimulation of proinflammatory enzymes, e.g., inducible nitric oxide synthase (iNOS), resulting in enhanced NO (nitric oxide) production [15,16]. In $\mathrm{AD}$, the expression of cyclooxygenase (COX-2, induced by proinflammatory mediators) is also upregulated [17], which results in increased production of inflammatory prostaglandins (PGs), especially PGE2, in the brain [18]. Increase in COX activity and PGE2 is also reported in aging brains. Because the PG synthesis pathway is a major source of reactive oxygen species (ROS) in the brain, inflammation may also be partly responsible for elevated oxidative stress in aging and AD. Several studies have suggested the association of chronic inflammation with other diseases, including CVD, diabetes, depression, Parkinson's disease (PD), and hypertension.

\section{Antioxidant and Anti-Inflammatory Components of Walnuts: Cumulative Effects}

Several lines of evidence suggest that walnuts (Juglans regia L.) may reduce the risk of age-related diseases because of the additive or synergistic effects of its components with antioxidant and anti-inflammatory effects. Walnuts have a high content $(3.68 \mathrm{mmol} / \mathrm{oz})$ of antioxidants, including flavonoids, phenolic acid (ellagic acid), melatonin, folate, gamma tocopherol (vitamin E), selenium, juglone, and proanthocyanidins [19-23]. In addition, walnuts contain a high amount of n-3 $\alpha$-linolenic acid (ALA), a plant-based omega-3 fatty acid that has a highly potent anti-inflammatory effect [23-26]. Walnuts also provide protein ( $4 \mathrm{~g} / \mathrm{oz})$, fiber $(2 \mathrm{~g} / \mathrm{oz})$, phosphorus (10\% daily value), and magnesium (11\% daily value).

Of 1113 different food items that were tested for their antioxidant contents, walnuts were ranked second place [21]. Among dry fruits, walnuts have the best antioxidant efficacy, as indicated by the fact that walnuts have the highest phenolic content, followed by almonds and cashew nuts and then raisins [27]. Another report indicated that $50 \mathrm{~g}$ of walnuts have significantly more phenolic content compared to an 8-oz glass of apple juice, 5-oz glass of red wine, or a milk chocolate bar [19].

Although most nuts contain monounsaturated fats, only walnuts have mainly polyunsaturated fat (13 $\mathrm{g}$ of $18 \mathrm{~g}$ total fat per $1 \mathrm{oz}$ walnuts), of which the ALA amount is $2.5 \mathrm{~g}$. ALA is the precursor for eicosapentaenoic acid (EPA) and docosahexaenoic acid (DHA), which are known to have anti-inflammatory effects. Studies have shown that ALA inhibits inflammation by downregulating iNOS (thus inhibiting NO production), COX-2, and inflammatory cytokines (IL-1 $\beta$, IL-6, TNF- $\alpha$ ) [23-26].

\section{Beneficial Effects of a Walnut-Enriched Diet on Cognitive Function}

Recent animal and human studies from our and other groups have suggested that long-term dietary supplementation with walnuts may reduce the risk or delay the onset/progression of MCI and AD. 


\subsection{Animal Studies}

$\mathrm{A} \beta$ is produced by the proteolysis of amyloid precursor protein (APP). APP-transgenic mice (AD-tg) with the APP gene mutation show memory deficit and $A \beta$ deposition in the brain and are considered an animal model of AD. The recommended daily serving of walnuts is 1-1.5 oz, i.e., $28-42 \mathrm{~g}$, which is equivalent to 12-18 walnut halves. We examined the effects of long-term (14 months) dietary supplementation with walnuts $(6 \%$ or $9 \%$ that equates to the recommended 1 oz or 1.5 oz of walnut intake per day in humans) on the memory, learning skills, motor coordination, and anxiety of AD-tg mice [28]. AD-tg mice on a control diet without walnuts showed memory deficit, anxiety-related behavior, and impairment in motor coordination, position discrimination learning ability and spatial learning ability in comparison to wild-type mice on the same diet. When fed to AD-tg mice, the diets supplemented with walnuts $(6 \%$ or $9 \%)$ showed an improvement in memory, learning skills, motor development, and anxiety-related behavior compared to a control diet without walnuts [28]. The diets for the control and experimental mice were comparable in terms of total calorie intake as well as protein, carbohydrate, and fat contents [28]. In another study with aged rats (19 months old), a diet with $6 \%$ walnuts was also reported to improve cognitive and motor performance [29].

\subsection{Clinical Trials in Humans}

In two PREDIMED (Prevención con Dieta Mediterránea) clinical trials from Spain, healthy adult subjects on a Mediterranean diet supplemented with $30 \mathrm{~g}$ mixed nuts/day (15 g walnuts, $7.5 \mathrm{~g}$ hazelnuts, and $7.5 \mathrm{~g}$ almonds) showed better cognitive function compared to the control group on a low-fat diet [30,31], and memory was significantly improved when compared to baseline scores in that group [31]. The participants in these studies were 522 adults (mean age: 74.6 years) [30] or 447 adults (mean age: 66.9 years) [31] at high cardiovascular risk but without any CVD or cognitive impairment. In the first study [30], global cognitive performance was assessed by the Mini-Mental State Examination (MMSE) and Clock Drawing Test (CDT) at the end of clinical trial after 6.5 years of dietary intervention, but baseline evaluation was not done. The second study examined rates of cognitive change with time by comparing scores from six different neuropsychological tests done at baseline and after 4.1 years of nutritional intervention [31].

In another clinical trial with older women, higher long-term intake of nuts (particularly walnuts) was reported to be associated with better cognitive performance [32]. In this study, 15,467 women (70 years of age or older; mean age: 74 years) participated. The difference in cognition scores between women who took five or more servings of nuts per week and women who did not consume nuts was equivalent to two years of cognitive aging. The National Health and Nutrition Examination Study (NHANES) of an adult population in the United States also showed better cognition scores with walnut consumption [33]. This study examined data from two different age groups (20-59 years; 60 years and older). Cognition scores were better with walnut consumption in both age groups.

Another study in 64 young adults examined the effects of short-term (8-week) dietary supplementation with walnuts on cognitive performance [34]. Memory, mood states, verbal reasoning, and non-verbal reasoning were assessed at baseline and at the end of the 8-week nutritional intervention period. There was a significant increase in inferential verbal reasoning in the subjects on the walnut-enriched diet, but there were no significant differences for mood, memory, or non-verbal reasoning. This may be because dietary supplementation of walnuts occurred for only eight weeks in this study.

\section{Mechanisms of Beneficial Effects of Walnuts on Cognition and Brain Disorders}

Figure 1 elucidates the potential mechanisms by which dietary supplementation of walnuts may reduce the risk, delay the onset and/or slow the progression of age-related cognitive decline, $\mathrm{MCI}$, and AD. 

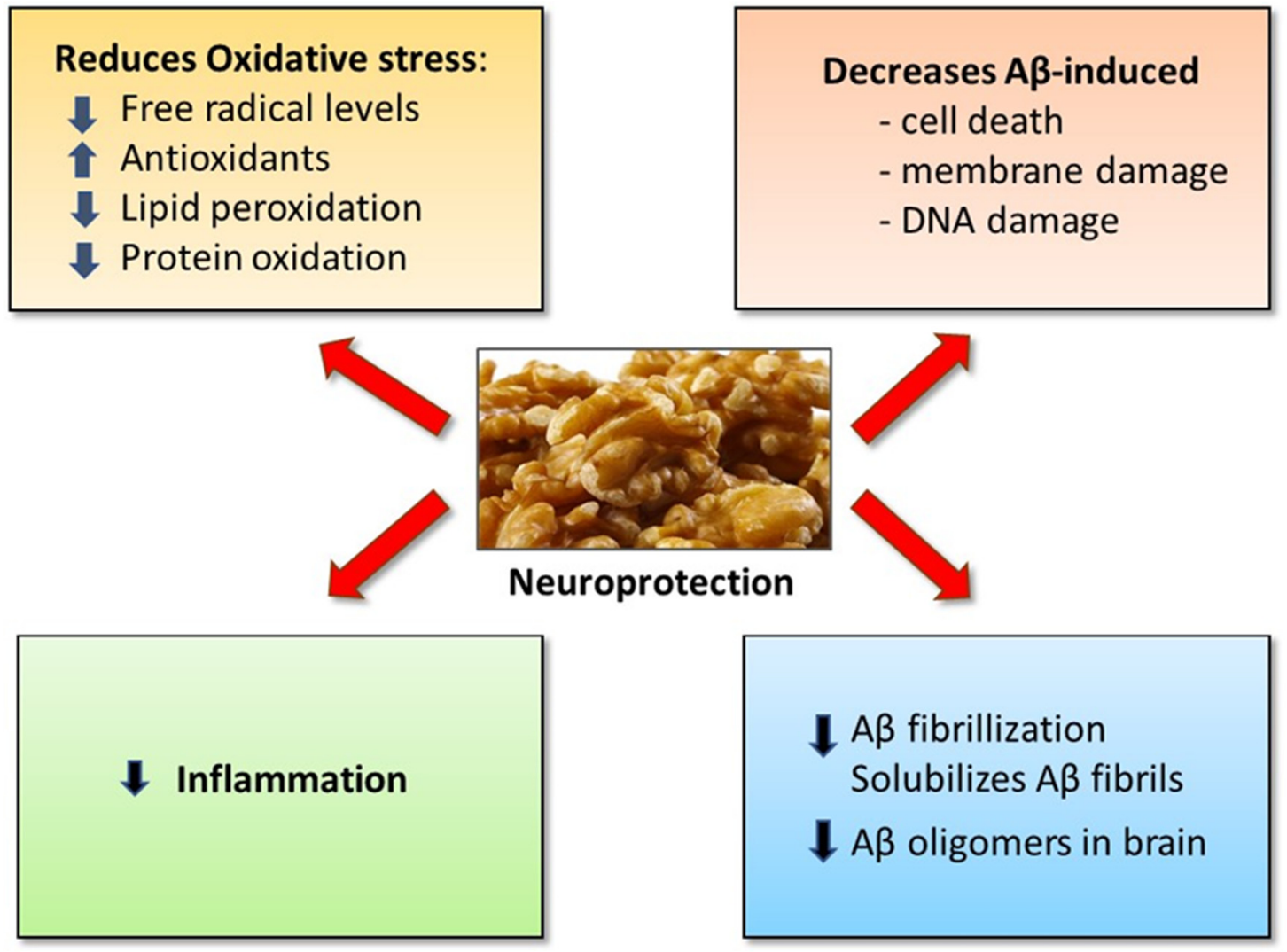

Figure 1. Potential mechanisms for neuroprotective effects of walnuts in reducing the risk of mild cognitive impairment (MCI) and dementia.

\subsection{Anti-Amyloidogenic Property of Walnuts: Walnuts Inhibit A $\beta$ Fibrillization and Solubilize A $\beta$ Fibrils}

The formation of $A \beta$ fibrils from soluble $A \beta$ is preceded by $A \beta$ oligomerization/aggregation, and it involves change in $A \beta$ conformation from $\alpha$-helical to $\beta$-pleated sheet structure. In a study with synthetic $A \beta$, walnut extract inhibited $A \beta$ fibrillization and solubilized preformed $A \beta$ fibrils. Here, thioflavin $T$ fluorescence spectroscopy was used to assess the degree of $A \beta$ aggregation/fibrillization, and the morphology of $\mathrm{A} \beta$ structure was examined by electron microscopy [35].

\subsection{Walnuts Decrease A $\beta$-induced Oxidative Stress and Cell Damage}

Many in vitro studies have reported that $\mathrm{A} \beta$ exhibits cytotoxic property by increasing ROS levels and inducing oxidative stress [14]. We have reported that walnut extract can protect against A $\beta$-induced oxidative stress and cell death [36]. In this study with PC12 pheochromocytoma cells, we examined the effects of walnut extract on $A \beta$-induced cell damage, ROS production, and apoptosis. The intracellular ROS accumulation caused by A $\beta$ treatment to the cells was significantly reduced in the presence of walnut extract when compared to $A \beta$-treated control cells without walnut extract. Walnut extract also decreased $A \beta$-mediated cell death (assessed by reduction of MTT (3-(4,5-dimethylthiazol-2-yl)-2,5-diphenyltetrazolium bromide), membrane damage (assayed by lactate dehydrogenase release), and DNA damage (apoptosis) in a dose-dependent manner [36]. These findings suggested that walnut extract can protect against $A \beta$-induced oxidative damage and associated cell death.

To further understand the mechanisms underlying the beneficial effects of dietary supplementation with walnuts in $\mathrm{AD}$, we recently studied whether short- or long-term supplementation with walnuts in the diet can reduce oxidative damage and/or enhance antioxidant defense in AD-tg mice [37]. AD-tg mice consuming a control diet without walnuts (T0) showed a significant age-dependent increase in ROS levels, lipid peroxidation, and protein oxidation, which was coupled with decreased activities of 
antioxidant enzymes (superoxide dismutase, catalase) compared to wild-type mice on the control diet. Oxidative stress was observed to be significantly reduced in AD-tg mice on diets with 6\% (T6) or 9\% walnuts (T9), as shown by lower levels of ROS, decreased lipid peroxidation and protein oxidation, and significant improvement in activities of antioxidant enzymes in these mice compared to control T0 mice. Long-term supplementation with walnuts in the diet for 10 or 15 months was found to be more effective in reducing ROS levels and oxidative damage to lipids and proteins and in improving antioxidant status in comparison with short-term supplementation with walnuts for 5 months in AD-tg mice [37].

In humans, acute consumption of walnuts was reported to increase total antioxidant capacity and to reduce plasma lipid peroxidation [38]. The components of walnuts, such as flavonoids, ellagic acid, gamma tocopherol, and melatonin, are known to have antioxidant and free-radical scavenging properties. Because components of walnuts have strong antioxidant properties, it is possible that the inhibition of $A \beta$-induced free radical levels by walnuts may be attributed to its effects on the neutralization of ROS.

\section{Potential Benefits of Walnuts in Other Brain Disorders and Chronic Diseases}

Oxidative stress and inflammation play pivotal roles not only in $\mathrm{MCI}$ and $\mathrm{AD}$, but also in other brain disorders, such as PD, depression, autism, schizophrenia, bipolar disorder, and several age-related chronic diseases.

\subsection{Walnuts and Parkinson's Disease, Depression, Stroke, and Epilepsy}

PD is characterized by the progressive loss of dopaminergic neurons and by clinical symptoms, including movement impairment, postural imbalance, tremor, and rigidity. In a mouse model of PD, walnut extract improved symptoms of PD (postural balance, motor coordination, and movement), reduced oxidative stress, and protected neurons [39].

Depression is quite common in people suffering from dementia, and it is considered a risk factor for dementia. More than $20 \%$ of people with dementia are also diagnosed with depression, and several other people show symptoms of depression. Cohort studies have shown an association between the number of depressive episodes and the risk of MCI and dementia [40]. In a 28-year follow-up study, symptoms of depression were mainly higher in the 10-year period before the diagnosis of dementia $[40,41]$. Recently, Arab et al. analyzed data on depression and walnut consumption from a NHANES study in the United States population [42]. They reported significantly fewer and less frequent depressive symptoms among subjects who included nuts, especially walnuts, in their diets as compared to a control group who did not take nuts. The subjects on a walnut-enriched diet showed greater interest in doing things, better concentration, higher energy levels, and less hopelessness. Sanchez-Vilegas et al. [43] also compared data on depression among PREDIMED subjects on a Mediterranean diet enriched with $30 \mathrm{~g} /$ day mixed nuts ( $15 \mathrm{~g}$ walnuts, $7.5 \mathrm{~g}$ hazelnuts, and $7.5 \mathrm{~g}$ almonds) or a control low-fat diet. This study population had men (age: 55-80 years) and women (age: 60-80 years) who were at higher risk of CVD but without any previously documented CVD; $51 \%$ of these subjects also had type 2 diabetes. When the entire group was compared, the risk of depression was reduced by $20 \%-30 \%$ (although it was not statistically significant) in the subjects who consumed a nut-enriched Mediterranean diet compared to the control group [43]. However, the risk of depression was significantly lower by $40 \%$ among people with diabetes in this group assigned to a Mediterranean diet supplemented with mixed nuts as compared to the control group [43]. The incidence of stroke was also found to be reduced by about $50 \%$ in the people who were on a Mediterranean diet supplemented with mixed nuts [44].

Epilepsy affects 50 million people worldwide and is defined by recurrent seizures. In experimentally induced epilepsy in rats, a walnut-enriched diet showed neuroprotective and anticonvulsant effects, and it also reduced mortality [45]. 


\subsection{Walnuts and Type 2 Diabetes}

It has been estimated that people with type 2 diabetes are more likely to develop dementia compared to non-diabetic individuals. A large cohort study of 83,818 women (age: 34-59 years) showed that dietary supplementation of $1 \mathrm{oz}$ of nuts, such as walnuts, five times or more per week decreased the risk of developing type 2 diabetes [46]. In two other large cohort studies with 58,063 women (age: 52-77 years) in the Nurses' Health Study (NHS) (1998-2008) and 79,893 women (age: 35-52 years) in NHS II (1999-2009), dietary supplementation of walnuts was associated with a significantly lower risk of type 2 diabetes [47]. The consumption of walnuts also significantly improved endothelial function in adults with type 2 diabetes [48]. The PREDIMED study of long-term intervention with a Mediterranean diet enriched with nuts also reported an association of nuts with a $50 \%$ reduction in diabetes [44].

\subsection{Walnuts and Cardiovascular Diseases}

The cardiometabolic risk factors that develop in mid-life (hypertension, obesity, hyperlipidemia) are also considered potential risk factors for cognitive decline and dementia. Several studies have suggested that walnuts in the diet can reduce the risk of heart disease by improving various cardiometabolic risk factors $[44,49,50]$. A walnut-enriched diet can decrease total and low-density lipoprotein (LDL) cholesterol, increase high-density lipoprotein (HDL) cholesterol, and reduce blood pressure, inflammation, and plaque formation [49-55]. Due to evidence in support of the benefits of walnuts related to cardiovascular health, the U.S. Food and Drug Administration approved the following health claim for walnuts in 2004: "Supportive but not conclusive research shows that eating 1.5 ounces of walnuts per day, as part of a low saturated fat and low cholesterol diet, and not resulting in increased caloric intake may reduce the risk of coronary heart disease."

\subsection{Walnuts and Body Weight}

Contrary to expectations, clinical trials, epidemiological studies, and systematic reviews of different studies have shown that walnut consumption in the diet does not contribute to weight gain or hinder weight loss goals as compared to a control diet $[49,53,56]$.

\section{Conclusions}

Oxidative stress and inflammation play important roles in the aging process, $\mathrm{MCI}$, dementia, and many age-related diseases. Walnuts have multiple components with antioxidant and anti-inflammatory effects, which may have additive or synergistic effects in suppressing inflammation and oxidative damage. Our studies have demonstrated that walnuts reduce oxidative stress not only by decreasing free radical levels but also by boosting antioxidant defense, thus reducing oxidative damage to lipids and proteins.

Substantial evidence from animal and human studies suggests that dietary consumption of walnuts (1-2 oz per day) can improve cognitive function and also reduce the risk of other diseases, such as cardiovascular disease, depression, and type 2 diabetes, which are risk factors for the development of dementia. Our studies in AD-tg mice have clearly demonstrated that long-term supplementation with walnuts in the diet can (a) significantly improve memory, learning skills, motor coordination, and anxiety-related behavior and (b) attenuate $A \beta$-induced oxidative stress by improving the balance between free radicals and antioxidants and associated $A \beta$-mediated cell death. Together, these reports suggest that early and long-term nutritional intervention with walnuts may have beneficial effects in maintaining cognitive function and protecting against age-related cognitive decline and in reducing the risk, delaying the onset, or slowing the progression of cognitive impairment and dementia in MCI and AD.

In order to clearly understand the mechanisms underlying the anti-amyloidogenic role of walnuts, further studies are warranted to investigate whether dietary walnuts can (a) affect the proteolytic 
cleavage of APP and inhibit $A \beta$ production and/or (b) increase $A \beta$ degradation by proteases, thus reducing the levels of $A \beta$ in the brain and increasing its clearance.

Author Contributions: Conceptualization, A.C.; writing—original draft preparation, A.C.; writing—review and editing, A.C. and V.C. All authors have read and agreed to the published version of the manuscript.

Funding: This work was supported by funds from the New York State Office for People with Developmental Disabilities.

Conflicts of Interest: The authors declare no conflicts of interest.

\section{References}

1. Livingston, G.; Sommerlad, A.; Orgeta, V.; Costafreda, S.G.; Huntley, J.; Ames, D.; Ballard, C.; Banerjee, S.; Burns, A.; Cohen-Mansfield, J.; et al. Dementia prevention, intervention, and care. Lancet 2017, 390, 2673-2734. [CrossRef]

2. Huang, H.C.; Jiang, Z.F. Accumulated amyloid-beta peptide and hyperphosphorylated tau protein: Relationship and links in Alzheimer's disease. J. Alzheimers Dis. 2009, 16, 15-27. [CrossRef] [PubMed]

3. Birben, E.; Sahiner, U.M.; Sackesen, C.; Erzurum, S.; Kalayci, O. Oxidative stress and antioxidant defense. World Allergy Organ. J. 2012, 5, 9-19. [CrossRef] [PubMed]

4. Chauhan, V.; Chauhan, A. Oxidative stress in Alzheimer's disease. Pathophysiology 2006, 13, 195-208. [CrossRef]

5. Bonda, D.J.; Wang, X.; Perry, G.; Nunomura, A.; Tabaton, M.; Zhu, X.; Smith, M.A. Oxidative stress in Alzheimer disease: A possibility for prevention. Neuropharmacology 2010, 59, 290-294. [CrossRef]

6. Wang, X.; Wang, W.; Li, L.; Perry, G.; Lee, H.G.; Zhu, X. Oxidative stress and mitochondrial dysfunction in Alzheimer's disease. Biochim. Biophys. Acta 2014, 1842, 1240-1247. [CrossRef]

7. Galasko, D.; Montine, T.J. Biomarkers of oxidative damage and inflammation in Alzheimer's disease. Biomark. Med. 2010, 4, 27-36. [CrossRef]

8. Schwab, C.; McGeer, P.L. Inflammatory aspects of Alzheimer disease and other neurodegenerative disorders. J. Alzheimers Dis. 2008, 13, 359-369. [CrossRef]

9. Agostinho, P.; Cunha, R.A.; Oliveira, C. Neuroinflammation, oxidative stress and the pathogenesis of Alzheimer's disease. Curr. Pharm. Des. 2010, 16, 2766-2778. [CrossRef]

10. Wang, W.Y.; Tan, M.S.; Yu, J.T.; Tan, L. Role of pro-inflammatory cytokines released from microglia in Alzheimer's disease. Ann. Transl. Med. 2015, 3, 136.

11. Schrag, M.; Mueller, C.; Zabel, M.; Crofton, A.; Kirsch, W.M.; Ghribi, O.; Squitti, R.; Perry, G. Oxidative stress in blood in Alzheimer's disease and mild cognitive impairment: A meta-analysis. Neurobiol. Dis. 2013, 59, 100-110. [CrossRef] [PubMed]

12. Pratico, D.; Clark, C.M.; Liun, F.; Rokach, J.; Lee, V.Y.; Trojanowski, J.Q. Increase of brain oxidative stress in mild cognitive impairment: A possible predictor of Alzheimer disease. Arch. Neurol. 2002, 59, 972-976. [CrossRef]

13. Torres, L.L.; Quaglio, N.B.; de Souza, G.T.; Garcia, R.T.; Dati, L.M.; Moreira, W.L.; Loureiro, A.P.; de Souza-Talarico, J.N.; Smid, J.; Porto, C.S.; et al. Peripheral oxidative stress biomarkers in mild cognitive impairment and Alzheimer's disease. J. Alzheimers Dis. 2011, 26, 59-68. [CrossRef]

14. Cai, Z.; Zhao, B.; Ratka, A. Oxidative stress and beta-amyloid protein in Alzheimer's disease. Neuromol. Med. 2011, 13, 223-250. [CrossRef] [PubMed]

15. Walker, D.G.; Link, J.; Lue, L.F.; Dalsing-Hernandez, J.E.; Boyes, B.E. Gene expression changes by amyloid beta peptide-stimulated human postmortem brain microglia identify activation of multiple inflammatory processes. J. Leukoc. Biol. 2006, 79, 596-610. [CrossRef] [PubMed]

16. Combs, C.K.; Karlo, J.C.; Kao, S.C.; Landreth, G.E. beta-Amyloid stimulation of microglia and monocytes results in TNFalpha-dependent expression of inducible nitric oxide synthase and neuronal apoptosis. $J$. Neurosci. 2001, 21, 1179-1188. [CrossRef]

17. Pasinetti, G.M.; Aisen, P.S. Cyclooxygenase-2 expression is increased in frontal cortex of Alzheimer's disease brain. Neuroscience 1998, 87, 319-324. [CrossRef]

18. Montine, T.J.; Sidell, K.R.; Crews, B.C.; Markesbery, W.R.; Marnett, L.J.; Roberts, L.J., 2nd; Morrow, J.D. Elevated CSF prostaglandin E2 levels in patients with probable AD. Neurology 1999, 53, 1495-1498. [CrossRef] 
19. Anderson, K.J.; Teuber, S.S.; Gobeille, A.; Cremin, P.; Waterhouse, A.L.; Steinberg, F.M. Walnut polyphenolics inhibit in vitro human plasma and LDL oxidation. J. Nutr. 2001, 131, 2837-2842. [CrossRef]

20. Fukuda, T.; Ito, H.; Yoshida, T. Antioxidative polyphenols from walnuts (Juglans regia L.). Phytochemistry 2003, 63, 795-801. [CrossRef]

21. Halvorsen, B.L.; Carlsen, M.H.; Phillips, K.M.; Bohn, S.K.; Holte, K.; Jacobs, D.R., Jr.; Blomhoff, R. Content of redox-active compounds (ie, antioxidants) in foods consumed in the United States. Am. J. Clin. Nutr. 2006, 84, 95-135. [CrossRef]

22. Reiter, R.J.; Manchester, L.C.; Tan, D.X. Melatonin in walnuts: Influence on levels of melatonin and total antioxidant capacity of blood. Nutrition 2005, 21, 920-924. [CrossRef] [PubMed]

23. Chauhan, A.; Chauhan, V. Potential beneficial effects of a diet with walnuts in aging and Alzheimer's disease. In Brain Aging and Therapeutic Interventions; Thakur, M.K., Rattan, S.I.S., Eds.; Springer: Dordrecht, The Netherland, 2012; pp. 239-252.

24. Ren, J.; Chung, S.H. Anti-inflammatory effect of alpha-linolenic acid and its mode of action through the inhibition of nitric oxide production and inducible nitric oxide synthase gene expression via NF-kappaB and mitogen-activated protein kinase pathways. J. Agric. Food Chem. 2007, 55, 5073-5080. [CrossRef] [PubMed]

25. Erdinest, N.; Shmueli, O.; Grossman, Y.; Ovadia, H.; Solomon, A. Anti-inflammatory effects of alpha linolenic acid on human corneal epithelial cells. Investig. Ophthalmol. Vis. Sci. 2012, 53, 4396-4406. [CrossRef] [PubMed]

26. Reifen, R.; Karlinsky, A.; Stark, A.H.; Berkovich, Z.; Nyska, A. Alpha-Linolenic acid (ALA) is an anti-inflammatory agent in inflammatory bowel disease. J. Nutr. Biochem. 2015, 26, 1632-1640. [CrossRef] [PubMed]

27. Mishra, N.; Dubey, A.; Mishra, R.; Barik, N. Study on antioxidant activity of common dry fruits. Food Chem. Toxicol. 2010, 48, 3316-3320. [CrossRef] [PubMed]

28. Muthaiyah, B.; Essa, M.M.; Lee, M.; Chauhan, V.; Kaur, K.; Chauhan, A. Dietary supplementation of walnuts improves memory deficits and learning skills in transgenic mouse model of Alzheimer's disease. J. Alzheimers Dis. 2014, 42, 1397-1405. [CrossRef]

29. Willis, L.M.; Shukitt-Hale, B.; Cheng, V.; Joseph, J.A. Dose-dependent effects of walnuts on motor and cognitive function in aged rats. Br. J. Nutr. 2009, 101, 1140-1144. [CrossRef]

30. Martinez-Lapiscina, E.H.; Clavero, P.; Toledo, E.; Estruch, R.; Salas-Salvado, J.; San Julian, B.; Sanchez-Tainta, A.; Ros, E.; Valls-Pedret, C.; Martinez-Gonzalez, M.A. Mediterranean diet improves cognition: The PREDIMED-NAVARRA randomised trial. J. Neurol. Neurosurg. Psychiatry 2013, 84, 1318-1325. [CrossRef]

31. Valls-Pedret, C.; Sala-Vila, A.; Serra-Mir, M.; Corella, D.; de la Torre, R.; Martinez-Gonzalez, M.A.; Martinez-Lapiscina, E.H.; Fito, M.; Perez-Heras, A.; Salas-Salvado, J.; et al. Mediterranean diet and age-related cognitive decline: A randomized clinical trial. JAMA Intern. Med. 2015, 175, 1094-1103, Erratum in: JAMA Intern. Med. 2018, 178, 1730-1732. [CrossRef]

32. O'Brien, J.; Okereke, O.; Devore, E.; Rosner, B.; Breteler, M.; Grodstein, F. Long-term intake of nuts in relation to cognitive function in older women. J. Nutr. Health Aging 2014, 18, 496-502. [CrossRef] [PubMed]

33. Arab, L.; Ang, A. A cross sectional study of the association between walnut consumption and cognitive function among adult US populations represented in NHANES. J. Nutr. Health Aging 2015, 19, 284-290. [CrossRef] [PubMed]

34. Pribis, P.; Bailey, R.N.; Russell, A.A.; Kilsby, M.A.; Hernandez, M.; Craig, W.J.; Grajales, T.; Shavlik, D.J.; Sabate, J. Effects of walnut consumption on cognitive performance in young adults. Br. J. Nutr. 2012, 107, 1393-1401. [CrossRef] [PubMed]

35. Chauhan, N.; Wang, K.C.; Wegiel, J.; Malik, M.N. Walnut extract inhibits the fibrillization of amyloid beta-protein, and also defibrillizes its preformed fibrils. Curr. Alzheimer Res. 2004, 1, 183-188. [CrossRef]

36. Muthaiyah, B.; Essa, M.M.; Chauhan, V.; Chauhan, A. Protective effects of walnut extract against amyloid beta peptide-induced cell death and oxidative stress in PC12 cells. Neurochem. Res. 2011, 36, 2096-2103. [CrossRef]

37. Pandareesh, M.D.; Chauhan, V.; Chauhan, A. Walnuts supplementation in the diet reduces oxidative damage and improves antioxidant status in transgenic mouse model of Alzheimer's disease. J. Alzheimer Dis. 2018, 64, 1295-1305. [CrossRef] 
38. Torabian, S.; Haddad, E.; Rajaram, S.; Banta, J.; Sabate, J. Acute effect of nut consumption on plasma total polyphenols, antioxidant capacity and lipid peroxidation. J. Hum. Nutr. Diet 2009, 22, 64-71. [CrossRef]

39. Choi, J.G.; Park, G.; Kim, H.G.; Oh, D.S.; Kim, H.; Oh, M.S. In vitro and in vivo neuroprotective effects of walnut (Juglandis Semen) in models of Parkinson's disease. Int. J. Mol. Sci. 2016, 17, 108. [CrossRef]

40. Dotson, V.M.; Beydoun, M.A.; Zonderman, A.B. Recurrent depressive symptoms and the incidence of dementia and mild cognitive impairment. Neurology 2010, 75, 27-34. [CrossRef]

41. Singh-Manoux, A.; Dugravot, A.; Fournier, A.; Abell, J.; Ebmeier, K.; Kivimaki, M.; Sabia, S. Trajectories of Depressive Symptoms Before Diagnosis of Dementia: A 28-Year Follow-up Study. JAMA Psychiatry 2017, 74, 712-718. [CrossRef]

42. Arab, L.; Guo, R.; Elashoff, D. Lower depression scores among walnut consumers in NHANES. Nutrients 2019, 11, 275. [CrossRef] [PubMed]

43. Sanchez-Villegas, A.; Martinez-Gonzalez, M.A.; Estruch, R.; Salas-Salvado, J.; Corella, D.; Covas, M.I.; Aros, F.; Romaguera, D.; Gomez-Gracia, E.; Lapetra, J.; et al. Mediterranean dietary pattern and depression: The PREDIMED randomized trial. BMC Med. 2013, 11, 208. [CrossRef] [PubMed]

44. Ros, E. Nuts and CVD. Br. J. Nutr. 2015, 113 (Suppl. 2), S111-S120. [CrossRef] [PubMed]

45. Asadi-Shekaari, M.; Kalantaripour, T.P.; Nejad, F.A.; Namazian, E.; Eslami, A. The anticonvulsant and neuroprotective effects of walnuts on the neurons of rat brain cortex. Avicenna J. Med. Biotechnol. 2012, 4, 155-158.

46. Jiang, R.; Manson, J.E.; Stampfer, M.J.; Liu, S.; Willett, W.C.; Hu, F.B. Nut and peanut butter consumption and risk of type 2 diabetes in women. JAMA 2002, 288, 2554-2560. [CrossRef]

47. Pan, A.; Sun, Q.; Manson, J.E.; Willett, W.C.; Hu, F.B. Walnut consumption is associated with lower risk of type 2 diabetes in women. J. Nutr. 2013, 143, 512-518. [CrossRef]

48. Ma, Y.; Njike, V.Y.; Millet, J.; Dutta, S.; Doughty, K.; Treu, J.A.; Katz, D.L. Effects of walnut consumption on endothelial function in type 2 diabetic subjects: A randomized controlled crossover trial. Diabetes Care 2010, 33, 227-232. [CrossRef]

49. Banel, D.K.; Hu, F.B. Effects of walnut consumption on blood lipids and other cardiovascular risk factors: A meta-analysis and systematic review. Am. J. Clin. Nutr. 2009, 90, 56-63. [CrossRef]

50. Kris-Etherton, P.M. Walnuts decrease risk of cardiovascular disease: A summary of efficacy and biologic mechanisms. J. Nutr. 2014, 144, 547S-554S. [CrossRef]

51. Sabate, J.; Fraser, G.E.; Burke, K.; Knutsen, S.F.; Bennett, H.; Lindsted, K.D. Effects of walnuts on serum lipid levels and blood pressure in normal men. N. Engl. J. Med. 1993, 328, 603-607. [CrossRef]

52. Ndanuko, R.N.; Tapsell, L.C.; Charlton, K.E.; Neale, E.P.; Batterham, M.J. Associations between dietary patterns and blood pressure in a clinical sample of overweight adults. J. Acad. Nutr. Diet. 2017, 117, 228-239. [CrossRef]

53. Guasch-Ferré, M.; Li, J.; Hu, F.B.; Salas-Salvadó, J.; Tobias, D.K. Effects of walnut consumption on blood lipids and other cardiovascular risk factors: An updated meta-analysis and systematic review of controlled trials. Am. J. Clin. Nutr. 2018, 108, 174-187. [CrossRef]

54. Estruch, R.; Ros, E.; Salas-Salvadó, J.; Covas, M.I.; Corella, D.; Arós, F.; Gómez-Gracia, E.; Ruiz-Gutiérrez, V.; Fiol, M.; Lapetra, J.; et al. Primary Prevention of Cardiovascular Disease with a Mediterranean Diet Supplemented with Extra-Virgin Olive Oil or Nuts. N. Engl. J. Med. 2018, 378, e34. [CrossRef]

55. Tindall, A.M.; Petersen, K.S.; Skulas-Ray, A.C.; Richter, C.K.; Proctor, D.N.; Kris-Etherton, P.M. Replacing saturated fat with walnuts or vegetable oils improves central blood pressure and serum lipids in adults at risk for cardiovascular disease: A randomized controlled-feeding trial. J. Am. Heart Assoc. 2019, 8, e011512. [CrossRef]

56. Neale, E.P.; Tapsell, L.C.; Martin, A.; Batterham, M.J.; Wibisono, C.; Probst, Y.C. Impact of providing walnut samples in a lifestyle intervention for weight loss: A secondary analysis of the HealthTrack trial. Food Nutr. Res. 2017, 61, 1344522. [CrossRef]

(C) 2020 by the authors. Licensee MDPI, Basel, Switzerland. This article is an open access article distributed under the terms and conditions of the Creative Commons Attribution (CC BY) license (http://creativecommons.org/licenses/by/4.0/). 